\title{
Effects of water deficit on leaf growth and initiation in fast-growing tree species
}

\author{
J.C. Metcalfe ${ }^{1}$, W.J. Davies ${ }^{1}$ and J.S. Pereira ${ }^{2}$ \\ 1 Institute of Environmental and Biological Sciences, University of Lancaster, Lancaster LA1 4 YQ, \\ U.K., and \\ 2 Department of Forestry, Instituto Superior de Agronomia, P-1399 Lisboa Codex, Portugal
}

\section{Introduction}

Eucalyptus globulus is becoming increasingly important in Mediterranean regions for pulpwood production. Although the plant is highly drought tolerant, its high productivity seems to be particularly sensitive to water shortage (Pereira et al., 1986). These researchers have shown that biomass production in young $E$. globulus growing in the field in Portugal can be increased by a factor of 3 under irrigation, and this has been related to an increase in foliage area (Borralho et al., 1987).

Most of our knowledge on the growth of tree seedlings to date comes from field experiments such as the above. In order to further our understanding of seedling growth, the early growth patterns of juvenile $E$. globulus have been investigated under conditions of water deficit, in conjunction with detailed measurements of gas exchange.

\section{Materials and Methods}

Experiments were conducted in Lisbon, Portugal, where E. globulus seedlings were grown outside in 51 plots of nutrient-rich soil. Plots were covered with plastic to prevent surface evaporation from the soil or rewetting by rain or dew. Plants were either watered to drip point every day or received no water from $d 0$. Leaf areas were calculated from regression equations constructed using caliper measurements of leaf length and width and direct values of leaf areas obtained with a $\mathrm{Li}$-cor leaf area meter. Gas exchange studies were conducted using a portable $\mathrm{CO}_{2} / \mathrm{H}_{2} \mathrm{O}$ porometer $(\mathrm{H}$. Walz Messund Regeltechnick, E:ffeltrich, F.R.G.).

\section{Results and Discussion}

Stomatal conductance and photosynthesis were both clearly reduced by soil drying (Fig. 1). Although the stomata opened at the beginning of the photoperiod, they stayed open for less time as water stress developed and, after $10 \mathrm{~d}$ without water, were almost closed in the afternoon. Photosynthesis appeared to decline linearly with conductance. In the longer term, a decline in biomass production under water shortage will result from reduced assimilation rates and a decrease in leaf area, and Borralho et al. (1986) recently reported that non-irrigated $E$. 

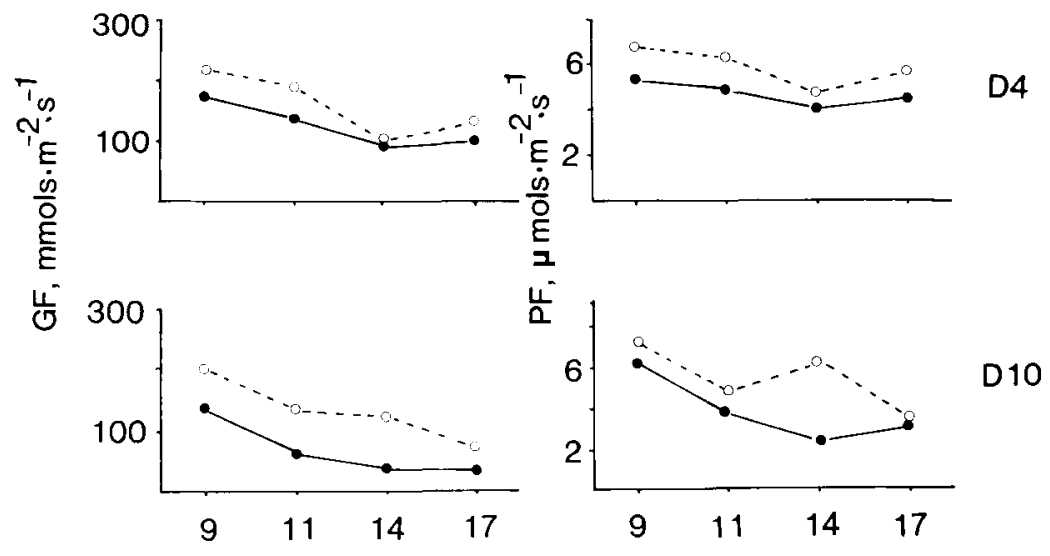

Hours

Fig. 1. Leal conductance $(G F)$ and photosynthesis $(P F)$ of well-watered $(0)$ and unwatered $(\bullet)$ E. globulus, 4 and $10 \mathrm{~d}$ after cessation of watering.

L7

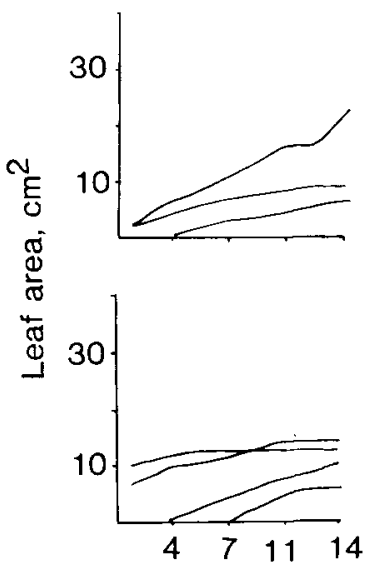

L8

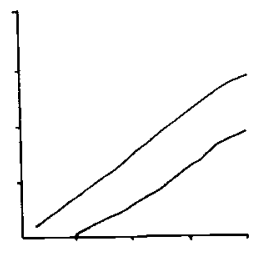

WW

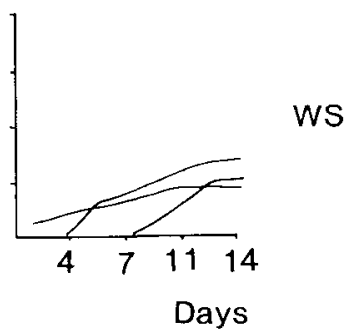

Fig. 2. Growth of individual leaves of well-watered (WW) and water-stressed (WS) E. globulus.

globulus had a smaller surface area per unit of leaf than did irrigated plants.

Provided the soil water deficit was not too severe, growth of the youngest leaves could still continue (Fig. 2), thus the reduction in dry matter production appears to be a result of more than purely a cessation of growth. Our current studies suggest that leaf initiation is important and, as demonstrated in Fig. 3, the initiation of new leaves at the apex of the dominant shoot is restricted with developing water stress. Indeed, Hsiao (1973) proposed that bud formation and leaf initiation were more sensitive than leaf growth to water deficit and these results tend to confirm that 


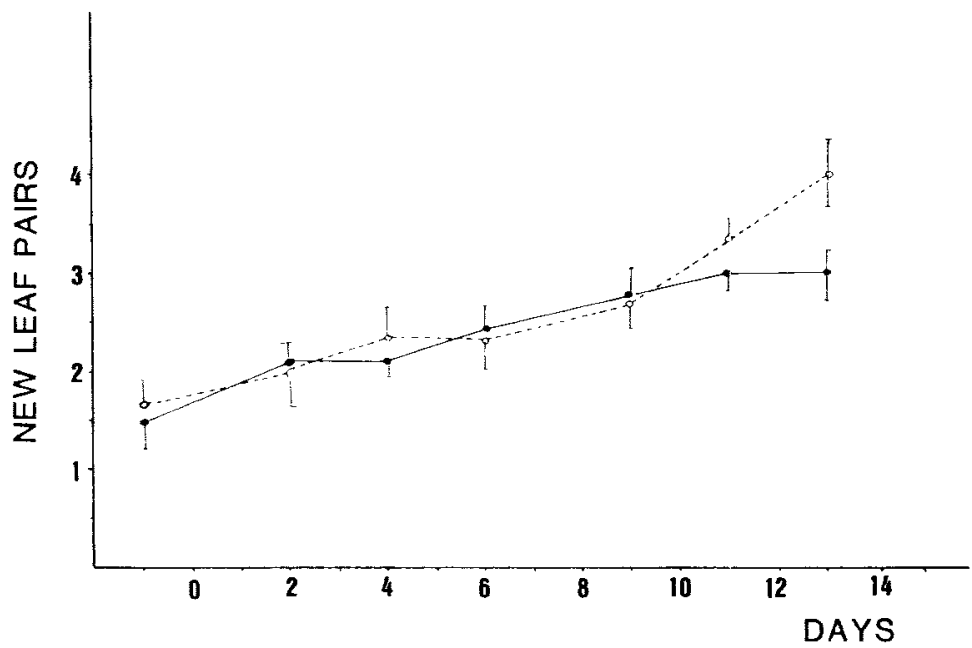

Fig. 3. Leal initiation in well-watered (- -) and unwatered $(-)$ E. globulus seedlings.

view. In addition, Pereira et al. (1987) have attributed the decreased foliage area observed with water shortage to decreased leaf number. Our understanding of the control of new leaf formation is limited at present and further research is being directed in this area.

\section{References}

Borralho N., Araújo M.C. \& Pereira J.S. (1987) Influence of water supply in crown structure and production of three clones of $E$. globulus in the juvenile phase. In: Structural and Functional Responses to Environmental Stresses: Water Shortage (Kreeb K.H., Richter H. \& Hinckley T.M., eds.), SFH Academic Publishing, The Hague

Hsiao T.C. (197:3) Plant responses to moderate water stress. Annu. Rev. Plant Physiol. 24, 519 570

Pereira J.S., Pereira H., Araújo M.C., Linder S., Ericsson T., Borralho N. \& Leal L. (1989) Optimisation of biornass production in $E$. globulus plantations. A case study. In: Biomass Production by Fast Growing Trees. (Pereira J.S. \& Landsberg J.J., eds.), Kluwer, Dordrecht, in press 